\title{
Molecular Detection of Rifampicin and Isoniazid Resistant Mycobacterium Tuberculosis and Their Associated Mutation Pattern From Smear Positive Sputum Samples From a Tertiary Care Centre of West U.P.
}

\author{
Mazher Maqusood ${ }^{1}$, Umar Farooq ${ }^{2}$, Sana Nudrat ${ }^{3}$ \\ ${ }^{1}$ Associate Professor, Department of Pulmonary Medicine, Teerthankar Mahaveer Medical College, Moradabad. 244001, U.P. INDIA, ${ }^{2}$ Professor and Head Dept. of \\ Microbiology, Teerthankar Mahaveer Medical College, Moradabad. 244001, U.P. INDIA, ${ }^{3}$ Ph.D. Scholar Dept. of Microbiology, Teerthankar Mahaveer Medical \\ College, Moradabad. 244001, U.P. INDIA.
}

\section{Abstract}

Background: Delayed diagnosis and treatment done on its basis has been proven to be a factor causing increase in rate of MDR TB. So we used GenoType MTBDR plus assay ${ }^{\circledR}$ in order to determine rate of MDR-TB, Isoniazid and Rifampicin mono resistance and common mutation pattern associated with them from our area in order to provide better patient care and reduce rate of MDR-TB. Subjects and Methods: This was a cross sectional prospective study comprising of 150 smear positive sputum samples collected during period of $11 / 2$ years from January 2018 to April 2019. Results: Out of total 150 smear positive samples 97 were from male patients and 53 from female patients. Rate of MDR TB found was 18/150 (12\%), rifampicin mono resistance and isoniazid mono resistance was 10/150 (6.6\%) and 13/150 (8.6\%) respectively. Highest percentage of MDR TB was seen among defaulter cases (27.3\%) followed by failure cases $(25 \%)$ and relapse cases (12.5\%). Mutation pattern most commonly reported for rifampicin is S531L in rpoB gene at codon 530-533 and for isoniazid was S315T1 in $k a t G$ gene at codon 315. Conclusion: Problem of MDR-TB is continuously rising, so rapid detection of TB along with drug sensitivity is the need of hour and should be given utmost priority for END TB strategy. The GenoType MTBDR plus (LPAs) assay approved by world health organization is highly specific ( $\geq 99 \%)$ and sensitive $(\geq 97 \%)$ diagnostic test for the detection of first line drugs resistance and is a rapid and reliable diagnostic tool.

Keywords: MDR-TB, LPA, rpo B, katG gene.

Corresponding Author: Dr. Mazher Maqusood, Associate Professor, Department of Pulmonary Medicine, Teerthankar Mahaveer Medical College, Moradabad. 244001, U.P. INDIA.

Received: June 2019

Accepted: June 2019

\section{Introduction}

Tuberculosis (TB) cases are on a continuous rise and create a major public health problem. India has the quarter burden of world's tuberculosis and has highest number of newly diagnosed cases annually recorded so, there is an urgent need for rapid detection of drug resistance among TB patients. ${ }^{[1]}$ Despite implementation of revised national tuberculosis control programme, free DOTS therapy and other meticulous effort by government TB control is still a challenge for all public sector officials and doctors associated with its control programme. Line Probe Assay (LPA) is a rapid technique which is based on combination of polymerase chain reaction (PCR) followed by the DNA reverse hybridization strip assay, that is used to detect Mycobacterium tuberculosis (MTB) complex as well as drug sensitivity to rifampicin and isoniazid in very short duration. ${ }^{[2,3]}$

Multidrug resistance tuberculosis arises due to random mutations which is seen or found in $r p o B$ and $k a t G$ genes and early detection of these mutation patterns is very helpful for diagnosis and giving the appropriate therapy to the patients. LPA technique does not require the organism growth, and can be performed directly on the clinical samples. Rifampicin and Isoniazid are the main drugs of first-line anti-TB therapy, and resistance to these drugs can result in treatment failure, increased treatment cost and poor prognosis. LPA technique, by targeting mutation at the 81base pair core region of the $r p o B$ gene for rifampicin resistant detection and additional for isoniazid resistant strains have mutations with $k a t G$ gene at codon 315. ${ }^{[4]}$

Aim and Objective: - In India various studies reported that, rate of MDR-TB is high and continuously rising and rapid detection can be a key to reduce this spread. So, we set out to determine rate of MDR-TB with their common mutation pattern and risk factors associated with drug resistant $\mathrm{TB}$ from this area using MTBDR plus GenoType assay.

\section{Subjects and Methods}

This was a cross sectional prospective study carried out in the Pulmonary Medicine Department and Molecular Section 
of Microbiology Department, comprising of 150 smear positive sputum samples collected during period of $1 \frac{1}{2}$ years from January 2018 to April 2019.

Sample Collection- Sputum samples were collected from the patients in a sterile, clear universal container who were attending OPD of pulmonary medicine department of Teerthankar Mahaveer Hospital\# and these samples were sent to molecular section of Microbiology department.

Case Selection- Patients included in the study were new cases having symptoms of $\mathrm{TB}$ or previously treated pulmonary TB cases suspected to be MDR-TB from all age groups. Previously treated patients were categorised into defaulter, relapse or failure cases. Defaulter cases were those who left treatment in between the course of DOTS therapy. Failure cases were those patients who were not cured by first line anti-tubercular drugs and Relapse cases were those patients who were cured completely but symptoms reoccurred in them.

Zeil-Neelson (ZN) staining was done on collected samples and only smear positive samples were further processed for decontamination.

Decontamination- was done by mixing $\mathrm{N}$-acetyl-Lcysteine (NALC) and Sodium hydroxide $(\mathrm{NaOH})$ with sample in equal volume. This mixture is used within 24 hours of preparation. ${ }^{[5]}$

DNA extraction- $500 \mu 1$ of the decontaminated specimen is taken in a microcentrifuge tube and centrifuged at 13000rpm for 15 minutes then supernatant was discarded and pellet is re-suspended in $100 \mu \mathrm{l}$ of molecular grade water and incubated in a heating bath at $95^{\circ} \mathrm{C}$ for 20 minutes. After this, it was kept in sonicator for 15 minutes. ${ }^{[5]}$

Mastermix Preparation- Master mix was prepared by combining the $5 \mu$ lextracted DNA with the specific primers (AM-A and AM-B) as per instruction in kit manual and then this mixture was kept in thermal cycler for amplification.

Amplification- Amplification was done in Veriti® 96 well thermocycler by Thermofisher ${ }^{\mathrm{TM}}$. For amplification denaturation was done for 15 minutes at $950 \mathrm{C}$ followed by annealing at $650 \mathrm{C}$ for 2 minutes and then extension at $700 \mathrm{C}$ for 30 seconds repeated for 20 times followed by a final extension at $700 \mathrm{C}$ for 8 minutes.

Hybridization- Hybridization was performed using hybridization kit of HAIN Life sciences ${ }^{\circledR}$ VER. 2.0 in a Twincubater / shaking water bath which is a semiautomatic washing and shaking device. Hybridization steps were performed using reagents provided with the kit as per manufacturer's instruction. ${ }^{[5]}$

\section{Results}

A total 150 sputum samples which were smear positive were included in this study, out of this $10(6.0 \%)$ and 13 $(8.6 \%)$ were rifampicin and isoniazid mono resistant respectively. $18(12.0 \%)$ cases were detected as Multi drug resistant (MDR). In our study a higher rate of rifampicin and isoniazid mono-resistance and MDR rate was found among male patients comparatively to female i.e. $7.2 \%$, $9.2 \%$ and $11.3 \%$ respectively. [Table 1]

Table 1: Sex-wise distribution of MDR and Mono drug resistant TB.

\begin{tabular}{|l|l|l|}
\hline Male & Female & Sensitivity \\
\hline $7(7.2 \%)$ & $3(5.6 \%)$ & RIF mono resistant $(\mathrm{n}=10 ; 6.0 \%)$ \\
\hline $9(9.2 \%)$ & $4(7.5 \%)$ & INH mono resistant $(\mathrm{n}=13 ; 8.6 \%)$ \\
\hline $11(11.3 \%)$ & $7(13.2 \%)$ & MDR $(\mathrm{n}=18 ; 12.0 \%)$ \\
\hline $70(72.3 \%)$ & $39(73.5 \%)$ & Sensitive to RIF \& INH $(\mathrm{n}=109 ; 72.6 \%)$ \\
\hline 97 & 53 & Total $(\mathrm{n}=150)$ \\
\hline
\end{tabular}

Table 2: Mono resistant and MDR status on the basis of treatment history.

\begin{tabular}{|l|l|l|l|l|}
\hline & Failure & Relapse & Defaulter & $\begin{array}{l}\text { New } \\
\text { cases }\end{array}$ \\
\hline $\begin{array}{l}\text { RIF mono } \\
\text { resistant (10) }\end{array}$ & $3(18.7 \%)$ & - & $4(12.1 \%)$ & $3(3.4 \%)$ \\
\hline $\begin{array}{l}\text { INH mono } \\
\text { resistant (13) }\end{array}$ & $1(6.2 \%)$ & $2(14.3 \%)$ & $6(18.1 \%)$ & $4(4.6 \%)$ \\
\hline MDR (18) to & $4(25 \%)$ & $2(14.3 \%)$ & $9(27.3 \%)$ & $3(3.4 \%)$ \\
\hline $\begin{array}{l}\text { Sensitive to } \\
\text { RIF \& INH } \\
(109) \text { 89 }\end{array}$ & $\begin{array}{l}(71.4 \%) \\
(150)\end{array}$ & $14(42.4 \%)$ & $\begin{array}{l}77 \\
(88.5 \%)\end{array}$ \\
\hline Total (150) & $\begin{array}{l}10.6 \%) \\
(10.6 \%)\end{array}$ & $33(22.0 \%)$ & $\begin{array}{l}87 \\
(58.0 \%)\end{array}$ \\
\hline
\end{tabular}

We also found in our study higher rate of rifampicin and isoniazid mono-resistant and MDR rate in defaulter category was $12.1 \%, 18.1 \%$ and $27.3 \%$ respectively followed by failure and relapse, So the chances of getting drug resistant TB is higher in defaulter cases. [Table 2]

Table 3: Age wise distribution.

\begin{tabular}{|l|l|l|l|l|}
\hline Age & $\begin{array}{l}\text { RIF mono } \\
\text { resistant }\end{array}$ & $\begin{array}{l}\text { INH mono } \\
\text { resistant }\end{array}$ & MDR & $\begin{array}{l}\text { Sensitive to } \\
\text { RIF \& INH }\end{array}$ \\
\hline $0-20$ & 1 & 2 & 2 & 15 \\
\hline $21-40$ & 2 & 5 & 5 & 23 \\
\hline $41-60$ & 5 & 4 & 6 & 44 \\
\hline $\begin{array}{l}\text { Above } \\
60\end{array}$ & 1 & 2 & 4 & 29 \\
\hline
\end{tabular}

In our study majority of patients were in age group of 41-60 years followed by above 60 years age group. [Table 3]

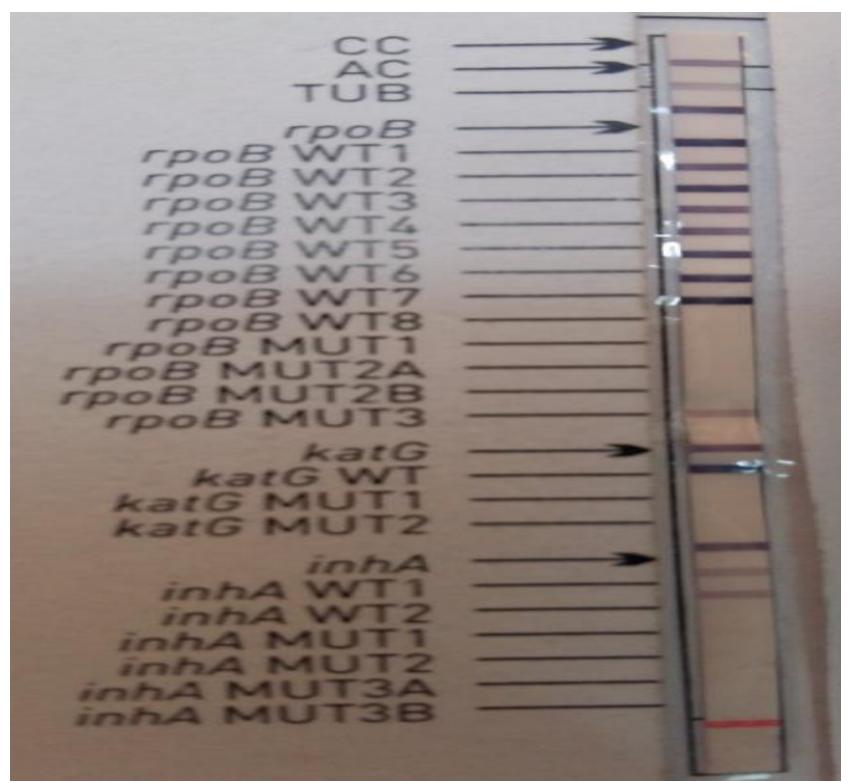

Figure 1: RIF mono resistant 


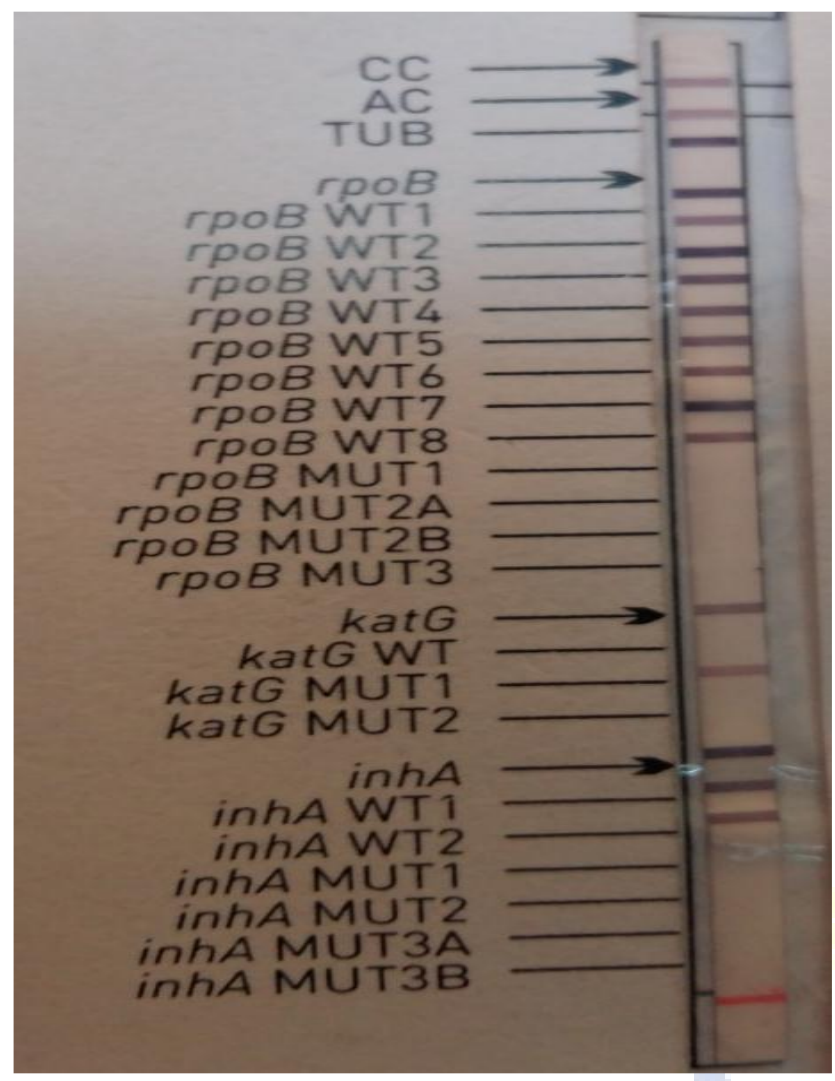

Figure 2: INH mono resistant

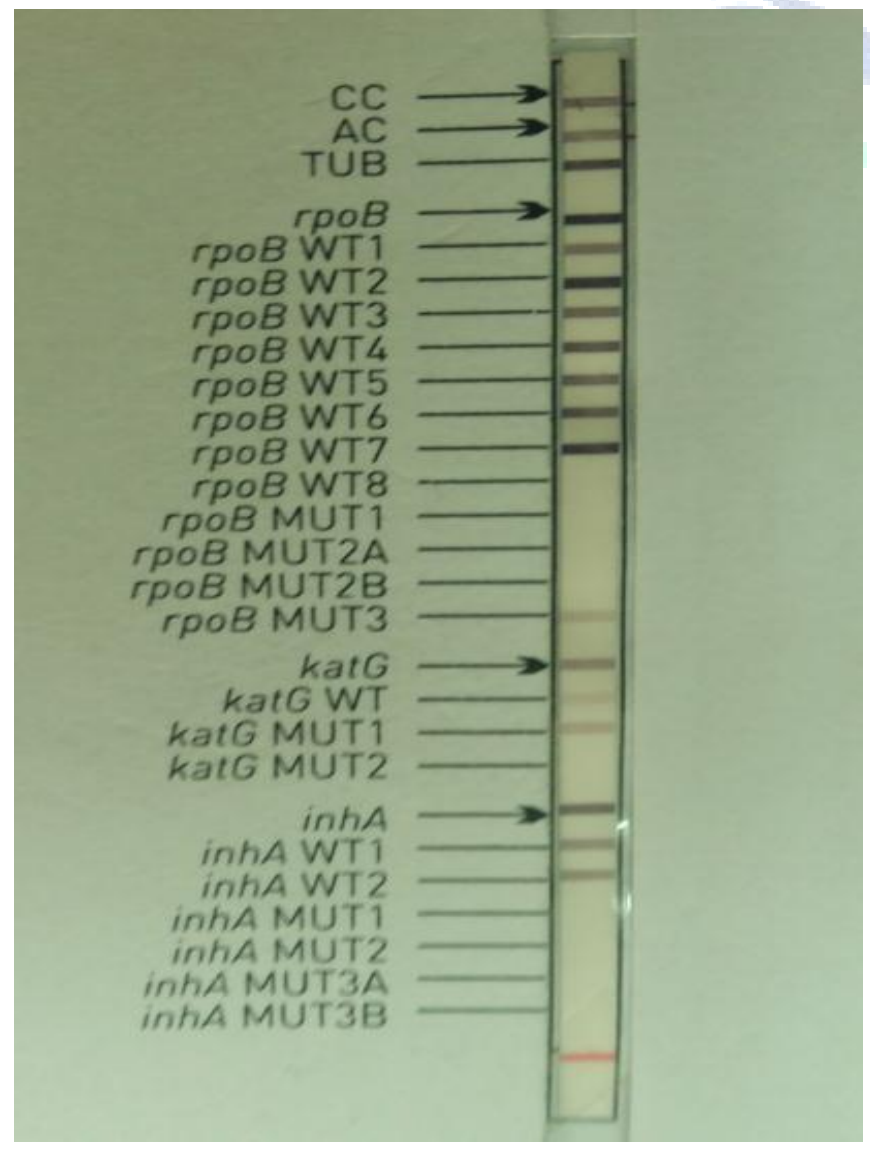

Figure 3: MDR
Mutation in rpoB gene: We found commonest mutation pattern causing rifampicin resistance was $\mathrm{S} 531 \mathrm{~L}$ in $r p o B$ gene at codon 530-533 which was in found in more than $80 \%$ cases of rifampicin mono resistant and Multi drug resistant tuberculosis (MDR- TB).

Mutation in $k a t G$ gene: Most common mutation pattern for isoniazid was S315T1 in katG gene at codon 315 which was found in more than $90 \%$ cases of isoniazid mono resistant and MDR-TB.

\section{Discussion}

In 2015-16, there is estimated 10.4 million new TB cases reported worldwide, of which 5.9 million were male and 3.5 million were female. One million Children were infected with TB. Smear microscopy is the major diagnostic tool for tuberculosis, especially in resource limited, high-TB burden developing countries such as India. However, the technique has low sensitivity and highly observer dependent, and is incapable in detecting drug resistance. ${ }^{[15]}$ So, there is need for rapid diagnostic tool, for detection of TB along with its resistance pattern. Here, we evaluated the utility of the latest LPA (version 2.0) for the rapid diagnosis of TB with their drug resistance pattern. ${ }^{[6]}$

In this study, we observed that TB infection rate was found more in male than female and the ratio of male to female was $2: 1$. Similarly, high male to female ratio was reported by Jatav $\mathrm{K}$ et al. ${ }^{[7]}$ This could be due to males are more commonly exposed to risk factors like smoking. Rate of rifampicin and isoniazid mono resistant was found in this study was $6 \%$ and $8.6 \%$ respectively, which is similar as reported by Singhal $\mathrm{R}$ at el ${ }^{[8]}$ in 2015 and Thakur $\mathrm{C}$ et al; ${ }^{[9]}$ in 2015 who reported, resistant to rifampicin is $4.6 \%$ and resistant to isoniazid $7.3 \%$ and rifampicin resistant rate of $6.1 \%$ and isoniazid resistant rate of $8.6 \%$ respectively. MDR TB rate found is $12 \%$ which is higher to study done by by Malhotra B et al; ${ }^{[10]}$ from Jaipur reported $4.5 \%$ and lower than the study done by Singhal S et al; ${ }^{[11]}$ in 2014 who reported MDR occurrence rate is $55 \%$. Rate of MDR $\mathrm{TB}$ is found high in defaulter cases than relapse and failure cases. This similar finding was reported by Ahmad S et $\mathrm{al}^{\left[{ }^{[12]}\right.}$ in Aligarh. This finding indicates that defaulter cases are high risk to get mono resistant and MDR.

Most common mutation pattern found in this study for rifampicin was S531L in $r p o B$ gene at codon 530-533, this similar finding is reported by Niudrat $\mathrm{S}$ et al; ${ }^{[13]}$ The second most common mutation pattern which is found in this study for isoniazid was S315T1 in katG gene at codon 315 and this finding is supported by Sharma BK. et al; ${ }^{[14]}$ in Nepal.

\section{Conclusion}

For sensitivity testing of both first line drugs LPA is the only method which is FDA approved and WHO endorsed rapid, sensitive and specific method for smear positive sputum samples. We found a high rate of MDR-TB from our area. This study highlights the need for quick identification and resistance pattern determination of 
tuberculosis cases on routine basis in order to reduce the current rate of MDR-TB and improve patient care. We also found there are high rates of RIF and INH mono resistance in this area which should be kept in mind while treatment. We also found there is increased risk of MDR-TB in defaulter category of patient, so appropriate TB control guidelines can be implemented to focus on this category of patients.

\section{References}

1. Jain A, Singh PK, Chooramani G, Dixit P, Malhotra HS. Drug resistance and associated genetic mutation among patients with suspected MDR-TB in Uttar Pradesh India. Int J Tuberc Lung Dis. 2016; 20(7): 870-5.

2. Kumar P, Balooni V, Singh S. Genetic mutations associated with rifampicin and isoniazid resistance in MDR-TB patients in North West India. Int J Tuberc Lung Dis. 2015; 19(4): 434-9.

3. Maurya AK, Singh AK, Kant S, Umrao J, Kumar M, Kushwaha RAS, et al. Use of GenoType MTBDRplus assay to assess drug resistance and mutation pattern of Multi drug resistant tuberculosis isolates in Northern India. J Med Microbiol. 2013; 31(3): 230-6.

4. Rufai SB, Kumar P, Singh A, Prajapati S, Balooni V, Singh S. Comparison of Xpert MTB/RIF with line probe assay for detection of rifampicin monoresistant Mycobacterium tuberculosis. J Clin Microbiol. 2014; 52(6): 1846-52.

5. Yacoob FL, Jose BP, Lelitha SD, Sreenivasan S. Primary Multidrug resistant tuberculosis and utility of Line probe assay for its detection in smear positive sputum samples in a tertiary care hospital in South India. J Pathog. 2016 Article ID: 6235618 Available from: https://www.hindawi.com/journals/jpath/2016/6235618/ (Last accessed 28 May 2019)

6. Ajbani K, Nikam C, Kazi M, Gray C, Boehme C, Balan K, et al. Evaluation of Genotype MTBDRplus assay to detect drug resistance associated with fluoroquinolones, aminoglycosides and ethambutol on clinical sediments. PLoS One. 2012; 7(11): e49433. available from: https://journals.plos.org/plosone/article?id=10.1371/journal.pone.0049 433 (Last accessed 20 May 2019)

7. Jatav K, Goel S, Farooq U, Krishna R, Nudrat S. Molecular detection of Mycobacterium tuberculosis complex from sputum samples of clinically suspected pulmonary tuberculosis patients. Int J Sci Res. 2018; 7(5): 27-9.

8. Singhal R, Myneed VP, Arora J, Singh N, Bhalla M, Verma A. et al. Early detection of multi drug resistance and common mutations in mycobacterium tuberculosis isolates from Delhi using GenoType MTBDRplus assay. Indian J Med Micro. 2015; 33(5): 46-52.

9. Thakur C, Kumar V, Gupta AK. Pattern of drug resistant Mycobacterium tuberculosis isolates in Himanchal Pradesh using Genotype MTBDR assay. Indian J Med Microbiol. 2015; 33(4): $547-$ 53.

10. Malhotra B, Pathak S, Vyas L, Katoch VM, Srivastava K, Chauhan DS, et al. Drug susceptibility profile of Mycobacterium tuberculosis isolates at Jaipur India J Med Microbiol. 2002; 20 (2): 76-8.

11. Singhal R, Prasad V, Arora J, Sinhg N, Sah G, Sarin R. Detection of multi drug resistance and characterization of mutation in Mycobacterium tuberculosis isolates from North Eastern States of India using genotype MTBDRplus assay. Indian J Med Res. 2014; 140 (4): 501-6.

12. Ahmed S, Shukla I, Fatima N, Vaeshney S, Shameem M. Evaluation of Genotype MTBD plus line probe assay in detection of rifampicin and isoniazid resistance in comparison to solid culture drug susceptibility testing in a tertiary care centre of western U.P. Indian J Med Microbiol. 2017; 35(4): 68-74.

13. Nudrat $\mathrm{S}$, Farooq U. Utility of Line probe assay for identification of MDR-TB and NTM in smear positive sputum samples from a tertiary care hospital of western U.P. India. Indian J Sci Res. 2017; 8(1): 1316.

14. Sharma BK, Bhandari S, Mahajan B, Shrestha B, Banjara MR. Rapid detection of rifampicin and isoniazid resistant Mycobacterium tuberculosis using genotype MTBDRplus assay in Nepal. Int Sch Res Notices. 2014 Oct. Article ID 648294. Available from: https://www.hindawi.com/journals/isrn/2014/648294/ (Last accessed 28 May 2019)

15. Singh BK, Sharma SK, Sharma R, Sreenivas V, Myneedu VP, Kohli $\mathrm{M}$, et al. Diagnostic utility of a line probe assay for multi drug resistant TB in smear negative pulmonary tuberculosis. PLOS One. 2017 Aug 22; 12(8): e0182988. Available from; https://www.ncbi.nlm.nih.gov/pmc/articles/PMC5568731/ (Last accessed 29 May 2019)

Copyright: () the author(s), 2019. It is an open-access article distributed under the terms of the Creative Commons Attribution License (CC BY 4.0), which permits authors to retain ownership of the copyright for their content, and allow anyone to download, reuse, reprint, modify, distribute and/or copy the content as long as the original authors and source are cited.

How to cite this article: Maqusood M, Farooq U, Nudrat S. Molecular Detection of Rifampicin and Isoniazid Resistant Mycobacterium Tuberculosis and Their Associated Mutation Pattern From Smear Positive Sputum Samples From a Tertiary Care Centre of West U.P. Asian J. Med. Res. 2019;8(2):PM05-PM08.

DOI: dx.doi.org/10.21276/ajmr.2019.8.2.PM2

Source of Support: Nil, Conflict of Interest: None declared. 